\title{
Morphology of the white-tailed deer tarsal gland
}

\author{
David A. OSBORN, Karl V. MILLER, Douglas M. HOFFMAN, \\ William H. DICKERSON, Jonathan W. GASSETT and Charlotte F. QUIST
}

\begin{abstract}
Osborn D. A., Miller K. V., Hoffman D. M., Dickerson W. H., Gassett J. W. and Quist C. F. 2000. Morphology of the white-tailed deer tarsal gland. Acta Theriologica 45: 117-122.
\end{abstract}

The communication of reproductive information in cervids is thought to be accomplished by odors associated with skin glands. The tarsal glands of white-tailed deer Odocoileus virginianus (Zimmerman, 1780), in particular, are the focus of many breeding behaviors and appear to attract the interest of conspecifics. These glands are annointed with urine with increasing frequency as the breeding season approaches and may convey social odors relating to dominance, reproductive condition, or individual recognition. We collected tarsal glands from male and female white-tailed deer of various ages during the breeding and non-breeding seasons. Using light microscopy, we examined skin biopsies of tarsal glands microscopically to quantify sebaceous and apocrine glandular activity. Measurements of sebaceous and apocrine glands did not differ between sexes or seasons, or among age classes. During the breeding season, the tarsal tufts of older males become darkly stained. Although the tarsal glands of white-tailed deer are important in conspecific communication, the staining and associated odors appears to be unrelated to variations in the sebaceous or apocrine gland activity. Rather, odor production on the tarsal gland likely results from interactions among urinary constituents, microbial decomposition, and glandular secretions.

Daniel B. Warnell School of Forest Resources, University of Georgia, Athens, GA 30602, USA, e-mail: jgassett@arches.uga.edu (DAO, KVM, WHD, JWG); USDA-APHIS, Wildlife Services, University of Georgia, Athens, GA 30602, USA (DMH); Athens Diagnostic Laboratory, University of Georgia, Athens, GA 30602 USA (ChFQ)

Key words: Odocoileus virginianus, apocrine, scent communication, sebaceous, tarsal gland

\section{Introduction}

In cervids, skin glands are a source of odors that communicate identity, social status, and reproductive information to conspecifics (Müller-Schwarze 1987). Skin glands typically are stimulated by testosterone and possibly inhibited by estrogens (Ebling 1977). Several species of deer have a raised tuft of hair on the medial aspect of each tarsus. This tarsal tuft and an underlying area of exocrine glandular tissue are collectively called the "tarsal organ" or "tarsal gland" (Müller-Schwarze 1987). Some deer urinate onto their tarsal glands in a behavior called rub-urination. Urine saturates the tarsal tuft and becomes trapped by specialized scent-disseminating hairs (Müller-Schwarze et al. 1977, Hoffman et al. 1997). These hairs facilitate the 
mixing of tarsal glandular secretions and urine, possibly producing unique odors (Müller-Schwarze et al. 1978).

Histology of the tarsal region has revealed sebaceous glands, apocrine glands, and erector pili muscles (Quay 1959, Quay and Müller-Schwarze 1970), with sebaceous glands located within the superficial layer of the dermis comprising the bulk of secretory elements. Apocrine glands, a less prominent feature of tarsal gland tissue, are located within a deeper dermal layer and are thought to contribute to the secretions of most mammalian scent glands (Quay 1984). Erector pili muscles of the tarsal gland provide erection of the tarsal tuft. These and possibly other structural components contribute to the overall function of the tarsal gland.

It is difficult to determine if pheromones exist in glandular secretions, urinary products, or both. In male black-tailed deer Odocoileus hemionus Rafinesque, 1817, a urinary product is retained selectively by tarsal glands (Brownlee et al. 1969). Previously, we investigated the volatile profiles of voided urine (Miller et al. 1998) of white-tailed deer Odocoileus virginianus (Zimmerman, 1780) and suggested that some volatile compounds from the tarsal gland may arise from microbial decomposition of urinary compounds and glandular secretions.

Functional activity of the tarsal gland may be influenced by age, sex, reproductive status, and social rank, as well as season and other variables. Determination of the relative contribution of glandular secretions and urinary products to tarsal odor production requires an understanding of the various influences on the activity of glandular tissues. Because previous quantification of tarsal tissues in white-tailed deer Odocoileus virginianus has been limited to a few animals collected during one season (Quay 1959), we evaluated the influence of age, sex, and season on the activity of apocrine and sebaceous tissues associated with the tarsal gland of the white-tailed deer.

\section{Methods}

We obtained tarsal glands from 52 male and 58 female white-tailed deer in the Piedmont physiographic region of Georgia between 22 September 1988 and 2 May 1989. We examined tooth replacement/attrition and used the technique of Severinghaus (1949) to place the deer into 1-year-old, 2 -year-old, and $\geq 3$-year-old age classes. Samples were fixed in $10 \%$ formalin for several days, rinsed in water for $24 \mathrm{hrs}$, and placed in $70 \%$ ethanol until processed. Season of collection was recorded as spring (March-May; non-breeding season) or fall (September-December; breeding season). Hair was shaved from the center of each tarsal gland, and a tissue sample $(5 \mathrm{~mm} \times 10 \mathrm{~mm})$ removed. The surface of the skin was embedded at a right angle to the cutting surface of a microtome. Nine serial transverse sections were cut from each block. Three sections were mounted per slide and stained with hematoxylin and eosin.

Area of sebaceous glands $\left(\mu \mathrm{m}^{2}\right)$ was measured using Planar Morphometry software (Microcomp Integrated Image Analysis System, Southern Micro Instruments, Inc., Atlanta, Ga.). Five fields of view were selected and examined from each deer. All sebaceous glands were measured in each field of view, and a total sebaceous gland area was calculated for each deer. We examined a subsample of skin sections (24 males, 27 females) to determine apocrine gland characteristics. Apocrine glands were measured with a computer-assisted image analyzer equipped with Data Image Analysis System software (C-squared Corp., Atlanta, Ga.). For each deer, we measured five well-defined apocrine glands 
in proximity to an associated hair follicle. Vertical distance from the skin surface to the closest tubule of the apocrine gland (Apocrine Gland Depth) and greatest vertical distance between opposite ends of the tubular portion of the apocrine gland (Apocrine Gland Length) were measured to the nearest $0.1 \mu \mathrm{m}$. Area of the apocrine gland (Apocrine Gland Area) was measured to the nearest $1.0 \mu \mathrm{m}^{2}$ by tracing the perimeter of the tubular portion of the gland. Thickness of apocrine secretory epithelium (Epithelium Thickness) was measured to the nearest $0.1 \mu \mathrm{m}$ at five locations and averaged. The number of apocrine tubular cross-sections with evidence of secretory activity was counted. Glands were considered active if the secretory epithelial cells possessed apical projections. A percentage of relative apocrine gland activity (Percent Apocrine Activity) was calculated by dividing the number of active cross-sections by the number of all cross-sections within the apocrine gland. Treatment effects were tested with analysis of variance (SAS Inst. 1989). When appropriate, data were rank or log transformed to compensate for heterogeneity of variances. Treatment significance was accepted at $p \leq 0.05$.

\section{Results and discussion}

Sebaceous gland area did not differ between sexes or seasons, or among age classes (Table 1). Similarly, apocrine gland depth, length, and area; epithelium thickness; and percent apocrine activity did not differ between sexes or seasons, or among ages (Table 2). We observed considerable variability in measurements among individuals. Furthermore, apocrine activity, based on apical projections, was inconsistent among glands of the same tissue sample. For example, one gland would suggest $100 \%$ activity, whereas the adjacent gland would suggest $0 \%$ activity.

Many potential factors may control the chemical nature of glandular secretions, including gene regulation, cell types and numbers, and androgen receptors. However, the lack of sexual or seasonal dimorphism in glandular activity suggests that important social odors may result from other sources. Instead, these glands may play an accessory role in the production and retention of scent on the tarsal

Table 1. Tarsal gland sebaceous area $(\bar{x} \pm \mathrm{SE})$ for white-tailed deer sampled during the reproductive (fall) and non-reproductive (spring) seasons from the Piedmont physiographic region of Georgia (1988-89). Measurements were taken to the nearest square micrometer $\left(\mu^{2}\right)$ at 5 microscopic fields per deer and then summed.

\begin{tabular}{lclrc}
\hline Sex & Age (Years) & Season & $n$ & $\begin{array}{c}\text { Sebaceous Gland } \\
\text { Area }\left(\mu \mathrm{m} \times 10^{4}\right)\end{array}$ \\
\hline Female & 1 & Fall & 3 & $3.09(2.06)$ \\
Female & 2 & Fall & 12 & $3.22(1.41)$ \\
Female & $\geq 3$ & Fall & 18 & $3.31(1.75)$ \\
Female & 1 & Spring & 4 & $2.75(2.50)$ \\
Female & 2 & Spring & 7 & $3.07(2.56)$ \\
Female & $\geq 3$ & Spring & 14 & $2.97(1.80)$ \\
Male & 1 & Fall & 5 & $2.87(3.85)$ \\
Male & 2 & Fall & 17 & $3.21(1.97)$ \\
Male & 1 & Fall & 23 & $2.81(1.51)$ \\
Male & 1 & Spring & 4 & $3.75(3.21)$ \\
Male & 2 & Spring & 3 & $4.75(9.61)$ \\
\hline
\end{tabular}


Table 2. Tarsal gland apocrine measurements $(\bar{x} \pm \mathrm{SE})$ for white-tailed deer sampled during the reproductive (fall) and non-reproductive (spring) seasons from the Piedmont physiographic region of Georgia (1988-89). ${ }^{a}$ Vertical distance from the skin surface to the closest tubule of the apocrine gland, measured to the nearest $0.1 \mu \mathrm{m}$. ${ }^{b}$ The greatest vertical distance between opposite ends of the tubular portion of the apocrine gland, measured to the nearest $0.1 \mu \mathrm{m}$. ${ }^{\mathrm{c}}$ Measured to the nearest $1.0 \mu \mathrm{m}$ by tracing the perimeter of the tubular portion of the gland. ${ }^{\mathrm{d}}$ Measured to the nearest $0.1 \mu \mathrm{m}$ it 5 locations within an apocrine gland. ${ }^{\mathrm{e}}$ Calculated by dividing the number of tubular cross-sections vith apical projections by the total number of cross-sections.

\begin{tabular}{|c|c|c|c|c|c|c|c|c|}
\hline \multirow[b]{2}{*}{ Sex } & \multirow[b]{2}{*}{$\begin{array}{c}\text { Age } \\
\text { (Years) }\end{array}$} & \multirow[b]{2}{*}{ Season } & \multirow[b]{2}{*}{$n$} & \multicolumn{3}{|c|}{ Apocrine Gland } & \multirow{2}{*}{$\begin{array}{c}\text { Epithelium } \\
\text { Thickness }^{\mathrm{d}} \\
(\mu \mathrm{m})\end{array}$} & \multirow{2}{*}{$\begin{array}{l}\text { Apocrine } \\
\text { Activity }^{\mathrm{c}} \\
(\%)\end{array}$} \\
\hline & & & & $\begin{array}{c}\text { Depth }^{\mathrm{a}} \\
\left(\mu \mathrm{m} \times 10^{3}\right)\end{array}$ & $\begin{array}{c}\text { Length }^{\mathrm{b}} \\
\left(\mu \mathrm{m} \times 10^{2}\right)\end{array}$ & $\begin{array}{c}\text { Area }^{\mathrm{c}} \\
\left(\mu \mathrm{m} \times 10^{5}\right)\end{array}$ & & \\
\hline Female & 1 & Fall & 5 & $2.44(0.23)$ & $8.56(1.09)$ & $3.34(0.71)$ & $11.3(0.5)$ & $17.5 \quad(9.4)$ \\
\hline Female & 2 & Fall & 5 & $2.56(0.13)$ & $7.88(0.75)$ & $3.30(0.73)$ & 12.0 & $25.0(18.9)$ \\
\hline Female & $\geq 3$ & Fall & 4 & $2.59(0.18)$ & $9.18(1.00)$ & $3.14(0.20)$ & $12.5(0.8)$ & $19.0 \quad(9.1)$ \\
\hline Female & 1 & Spring & 4 & $2.11(0.14)$ & $6.66(0.20)$ & $2.91(0.28)$ & $13.2(1.4)$ & 46.2 (19.7) \\
\hline Female & 2 & Spring & 4 & $2.48(0.15)$ & $8.21(0.99)$ & $3.51(0.41)$ & $17.1(3.0)$ & $52.0(17.9)$ \\
\hline Female & $\geq 3$ & Spring & 5 & $2.35(0.10)$ & $7.15(0.47)$ & $2.85(0.52)$ & $12.3(0.6)$ & $14.5(14.5)$ \\
\hline Male & 1 & Fall & 4 & $2.56(0.21)$ & $7.76(0.50)$ & $2.83(0.17)$ & $10.8(0.5)$ & $0.0 \quad(0.0)$ \\
\hline Male & 2 & Fall & 5 & $2.03(0.41)$ & $8.23(0.93)$ & $3.62(0.62)$ & $12.4(1.1)$ & $5.1 \quad(3.0)$ \\
\hline Male & $\geq 3$ & Fall & 8 & $2.49(0.20)$ & $9.72(0.83)$ & $3.82(0.59)$ & $12.1(0.8)$ & $22.3(11.0)$ \\
\hline Male & 1 & Spring & 4 & $1.99(0.53)$ & $7.58(0.83)$ & $3.13(0.34)$ & $12.0(0.4)$ & $13.8 \quad(8.5)$ \\
\hline Male & 2 & Spring & 3 & $2.41(0.13)$ & $7.76(0.03)$ & $3.60(0.61)$ & $14.9(3.4)$ & $24.3(24.3)$ \\
\hline
\end{tabular}

tuft. For instance, lipid secretions from the sebaceous glands, when distributed to the tarsal tuft (Hoffman et al. 1997), may selectively adsorb fat-soluble urinary constituents and metabolic products of bacterial decomposition important in intraspecific communication (Gassett and Miller 1997, Gassett et al. 1998).

The amount of individual variation in our sebaceous and apocrine gland measurements is consistent with results from a similar study of reindeer (Mossing and Kallquist 1981). We agree that, even when a large sample of individuals froma population shows no treatment related glandular change, differences may be evident in another sample or another population. These differences may be related to age, hormonal history, genetic or other factors increasing the size of preexistirg gland units (Quay 1984). However, for this group of white-tailed deer, we found ro evidence of sex, age, or season-related glandular activity.

During the fall, older males tend to have darker tarsal tufts than younger males or females of any age. The dark color and pungent odor of tarsal glands of dominant males during the breeding season is evident through casual observation (Moore and Marchinton 1974). White-tailed deer of all ages rub-urinate, but the behavior is most common among dominant males during the breeding season (Marchinton st al. 1990). Tarsal glands of dominant males also have more species of microbes than those of subordinate males or females (Gassett and Miller 1997). We suggest that darkly stained tarsal tufts are not the result of increased glandular activity, but 
rather the result of frequent exposure to voided urine and subsequent bacterial decomposition, or differences in urinary components.

The tarsal glands of deer in the genus Odocoileus may relay information on age, sex, and individual recognition, as well convey social status. Volatile profiles of the tarsal tuft (J. W. Gassett, unpubl. data) and voided urine (Miller et al. 1998) of white-tailed deer vary among season, sex, and age classes, and frequent rub-urination likely is necessary to maintain semiochemical cues (Sawyer et al. 1993). Because we found no age, sex, or season-related variation in the activity of the underlying glandular tissues, we feel that the activity of the glands themselves probably have an ancillary or accessory role in the production of socially significant odors. Although a number of alternate hypotheses exist as to the source of tarsal odors, we feel a likely scenario is that volatile compounds from the tarsal region may result, at least in part, from microbial decomposition of urinary compounds and glandular secretions. This hypothesis is further supported by recent studies in which 18 species of bacteria were cultured and identified from the tarsal tuft that were specific to that region of the animal (Gassett and Miller 1997).

Acknowledgments: This research was supported by McIntire-Stennis project number GEO-0093-MS and donations from Wellington Outdoors. We thank E. C. Player for tissue preparation; G. N. Rowland and D. M. Miller for use of their image analyzers; and R. L. Marchinton, S. Odend'hal, and E. E. Provost for their assistance with a previous version of this manuscript.

\section{References}

Brownlee R. G., Silverstein R. M., Müller-Schwarze D. and Singer A. G. 1969. Isolation, identification and function of the chief component of the male tarsal scent in black-tailed deer. Nature 221: 284-285.

Ebling F. J. 1977. Hormonal control of mammalian skin glands. [In: Chemical signals in Vertebrates. D. Müller-Schwarze and M. M. Mozell, eds]. Plenum Press, New York: 17-31.

Gassett J. W. and Miller K. V. 1997. Odour production from the tarsal glands of male white-tailed deer. [In: Proceedings of the 31st International Congress of the International Society of Applied Ethology, 13-16 August 1997. P. H Hemsworth, M. Spinka and L. Kostal, eds]. Prague, Czech Republic: 149 .

Gassett J. W., Dasher K. A. and Miller K. V. 1998. Microbial production of breeding odors in male white-tailed deer. [In: Proceedings of the 78th Annual Meeting of the American Society of Mammalogists, 6-10 June 1998]. Blacksburg, Virginia: Abstract 137.

Hoffman D. M., Miller K. V., Marchinton R. L. and Osborn D. A. 1997. Ultrastructure of hairs associated with the skin glands of white-tailed deer (Odocoileus virginianus). Georgia Journal of Science 55: 209-214.

Marchinton R. L., Johansen K. L. and Miller K. V. 1990. Behavioural components of white-tailed deer scent marking: social and seasonal effects. [In: Chemical Signals in Vertebrates 5. D. W. Macdonald, D. Müller-Schwarze and S. E. Natynczuk, eds]. Oxford University Press, United Kingdom: 295-301.

Miller K. V., Jemiolo B., Gassett J. W., Jelinek I., Wiesler D. and Novotny M. 1998. Putative chemical signals from the white-tailed deer (Odocoileus virginianus): social and seasonal effects on urinary volatile excretion in males. Journal of Chemical Ecology 24: 673-683.

Moore W. G. and Marchinton R. L. 1974. Marking behavior and its social function in white-tailed deer. [In: The behaviour of ungulates and its relation to management. V. Geist and F. Walther, eds]. 
International Union on the Conservation of Nature and Natural Resources, Morges, Switzerland, New Series, Publication 24: 447-456.

Mossing T. and Kallquist L. 1981. Variation in cutaneous glandular structures in reindeer (Rangifer tarandus). Journal of Mammalogy 62: 606-612.

Müller-Schwarze D. 1987. Evolution of cervid olfactory communication. [In: Biology and Management of the Cervidae. C. M. Wemmer, ed]. Smithsonian Inst. Press, Washington, District of Columbia: 223-234.

Müller-Schwarze D., Volkman N. J. and Zemanek K. F. 1977. Osmetrichia: specialized scent hair in black-tailed deer. Journal of Ultrastructure Research 59: 223-230.

Müller-Schwarze D., Ravid U., Claesson A. L. F., Singer A. G., Silverstein R. M., Müller-Schwarze C., Volkman N. J., Zemanek K. F. and Butler R. G. 1978. The deer lactone: source, chemical properties, and responses by black-tailed deer. Journal of Chemical Ecology 4: 247-256.

Quay W. B. 1959. Microscopic structure and variation in the cutaneous glands of the deer, Odocoileus virginianus. Journal of Mammalogy 40: 114-128.

Quay W. B. 1984. Scent glands. [In: Biology of the Integument 2: Vertebrates. J. Bereiter-Hahn, A. G. Matoltsy and K. S. Richards, eds]. Springer-Verlag, Berlin, Germany: 357-369.

Quay W. B. and Müller-Schwarze D. 1970. Functional histology of integumentary glandular regions in black-tailed deer (Odocoileus hemionus columbianus). Journal of Mammalogy 51: 676-694.

SAS Institute Inc. 1989. SAS/STAT user's guide. Version 6. SAS Inst., Inc., Gary, North Carolina: $1-846$.

Sawyer T. G., Miller K. V. and Marchinton R. L. 1993. Patterns of urination and rub-urination in female white-tailed deer. Journal of Mammalogy 74: 477-479.

Severinghaus C. W. 1949. Tooth development and wear as criteria of age in white-tailed deer. The Journal of Wildlife Management 13: 195-216.

Received 19 October 1998, accepted 10 May 1999. 